\title{
DETAILED ANALYSIS OF A QUENCH BOMB FOR THE STUDY OF ALUMINUM AGGLOMERATION IN SOLID PROPELLANTS
}

\author{
S. Gallier, J.-G. Kratz, N. Quaglia, and G. Fouin \\ SAFRAN-Herakles \\ Le Bouchet Research Center \\ Vert-le-petit 91710, France
}

\begin{abstract}
A standard quench bomb (QB) - widely used to characterize condensed phase from metalized solid propellant combustion - is studied in detail. Experimental and numerical investigations proved that collected particles are mostly unburned aluminum (Al) agglomerates despite large quenching distances. Particles are actually found to quench early as propellant surface is swept by inert pressurant. Further improvements of the $\mathrm{QB}$ are proposed which allow measuring both $\mathrm{Al}$ agglomerates and alumina residue with the same setup. Finally, the results obtained on a typical aluminized ammonium perchlorate (AP) / hydroxyl-terminated polybutadiene (HTPB) propellant are briefly discussed.
\end{abstract}

\section{INTRODUCTION}

Typical solid propellants for industrial applications are composed of AP as well as $\mathrm{Al}$ particles embedded in a fuel binder. During solid propellant combustion, agglomeration of $\mathrm{Al}$ is likely to occur: $\mathrm{Al}$ particles may sinter and/or coalesce as the heat wave passes by and this leads to $\mathrm{Al}$ agglomerates whose size $D_{\text {agg }}$ is much larger than initial virgin $\mathrm{Al}$ introduced in propellant. In spite of many studies, the physics of agglomeration is intricate and not completely understood so far [1-4]. As far as the authors know, there exist no models able to predict accurately agglomeration although some interesting microstructure-based approaches have been proposed recently $[5,6]$. Those large $\mathrm{Al}$ agglomerates are subsequently ejected into the chamber flow where they melt and then react in the gas flow in a diffusion flame and eventually end up as $\mathrm{Al}$ oxide residues (alumina, $\mathrm{Al}_{2} \mathrm{O}_{3}$ ) after combustion. A detailed study of $\mathrm{Al}$ combustion may be found in $[3,7]$. Figure 1 depicts the process of $\mathrm{Al}$ agglomeration and combustion and illustrates that there are mainly three distinct particle populations with different diameters: (i) Al agglomerates with $D_{\text {agg }} \sim \mathrm{O}(100 \mu \mathrm{m})$; (ii) final $\mathrm{Al}_{2} \mathrm{O}_{3}$ residues with 


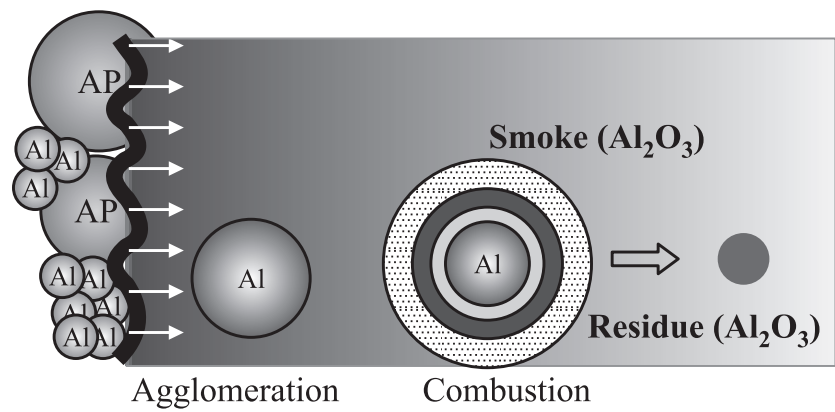

Figure 1 Sketch depicting the process of $\mathrm{Al}$ agglomeration and combustion

$D_{\text {res }} \sim \mathrm{O}(10 \mu \mathrm{m})$; and $($ iii $) \mathrm{Al}_{2} \mathrm{O}_{3}$ smoke with $D_{\text {smoke }} \sim \mathrm{O}(1 \mu \mathrm{m})$. Note that there are also $\mathrm{Al}$ particles - not represented in Fig. 1 - that leave the combustion surface unagglomerated. The physical origin of the final oxide residue is hitherto not clear and it cannot be explained solely by the initial alumina passivation layer on $\mathrm{Al}$ particles.

The presence of this distinct two-phase feature makes the flow in a solid rocket quite complex to understand. In particular, the resulting two-phase flow has significant impacts on steady performance because of two-phase losses in nozzle, slag accumulation, or nozzle erosion [8-10]. Additionally, it also has some profound effects on unsteady motor operation. Although particles are generally employed for instability damping, recent research [11] showed that large burning agglomerates are prone to trigger thermoacoustic instabilities in solid rocket motors. Because the role of particles on motor operation can be significant, those particles need to be characterized accurately - notably, size and mass fraction. This is instrumental in providing reliable input data for numerical simulations. As mentioned above, the underlying physics of agglomeration or formation of residue is not known sufficiently for reliable predictions, so that particle size must be obtained experimentally. The present authors insist on the fact that both $\mathrm{Al}$ agglomerate size and $\mathrm{Al}_{2} \mathrm{O}_{3}$ final residue size must be measured since both of them play a major role.

A common way to collect and study the condensed phase from propellant combustion is the QB [12-14] where the particles from propellant surface are quenched, usually in liquid. Actually, experimental methods have been adopted either through simulated motors (such as QBs), or directly in subscale motor chambers, or in plume exhausts. However, direct measurements in motors are complex as the collection must be isokinetic in order not to bias the size distribution [15] whereas the measurements in the plume are somewhat irrelevant because of possible breakup and coalescence of particles. Therefore, QB appears as a simple and relevant setup to provide information on particle phase. 
In this paper, the results obtained with a standard QB are studied and, especially, the focus is made on the nature of the particles collected. It was found that the present $\mathrm{QB}$ does collect $\mathrm{Al}$ agglomerates rather than alumina residue and the present authors subsequently propose an improved version that allows to measure both agglomerates and oxide residues.

\section{QUENCH BOMB RESULTS}

\subsection{Description of Setup}

The QB setup used in the frame of this study is described in Fig. 2. It is composed of a drum (diameter $132 \mathrm{~mm}$ ) placed in a pressurized vessel. The pressurant used is nitrogen $\left(\mathrm{N}_{2}\right)$ at ambient temperature and with a pressure prescribed between 0.1 and $14 \mathrm{MPa}$. The solid propellant sample is a cube of size $10 \mathrm{~mm}$ (mass $\sim 1.5-2 \mathrm{~g}$ ) and is placed inside the drum through a sampleholder as depicted in Fig. 2. The drum is partially filled with a quenching liquid (here, ethanol) and is then rotated at high speed so that the ethanol is centrifuged against the side wall of the drum. Typical rotation rate is $3000 \mathrm{rpm}$ and the resulting thickness of the ethanol film is estimated to be about $2-3 \mathrm{~mm}$. Ethanol is chosen since it is known to minimize flocculation of fine alumina smoke. The propellant sample is positioned horizontally so that it faces the moving wall of the quenching fluid. Note that the sample is inhibited except on the surface that faces the wall. The propellant is then ignited and burns towards the wall so that condensed-phase products from propellant combustion are quenched in the ethanol film. The distance $d_{\text {quench }}$ between initial propellant surface and ethanol film can be varied from 3 to about $60 \mathrm{~mm}$. A distance $d_{\text {quench }}=40 \mathrm{~mm}$

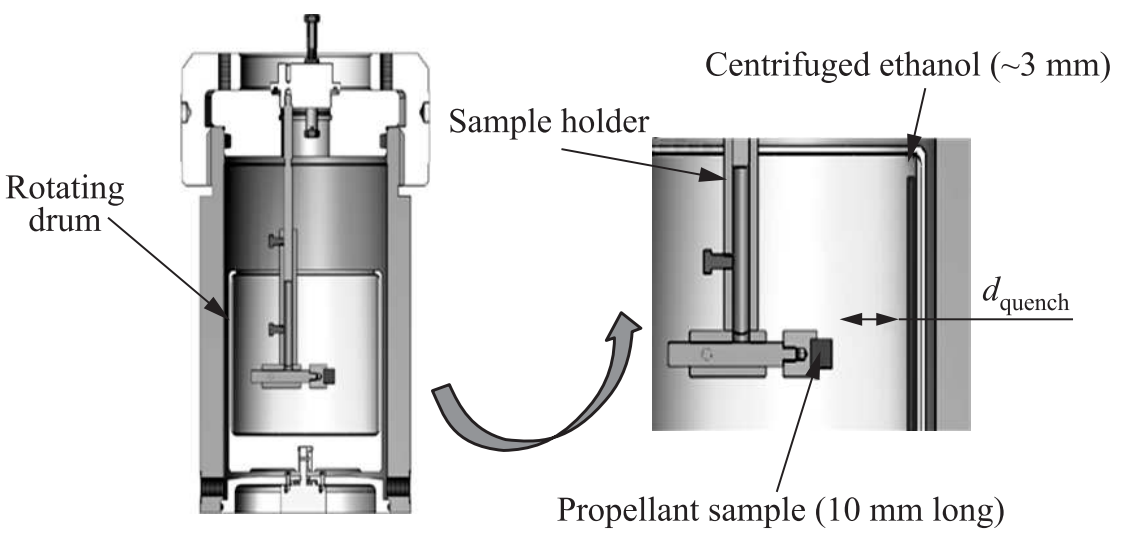

Figure 2 Sketch of the standard QB (left) and zoom in the propellant area (right) 
is generally chosen as it is believed to be sufficient for combustion completion. For a $D_{\text {agg }}=100 \mu \mathrm{m} \mathrm{Al}$ agglomerate, the burn time is typically $20-30 \mathrm{~ms}[7]$ which represents at most a combustion distance of $30 \mathrm{~mm}$ for a particle velocity $U_{p} \sim 1 \mathrm{~m} / \mathrm{s}$. After the propellant has burned out, the setup is depressurized and the ethanol suspension containing the particles can be further analyzed.

The particle analysis includes laser size granulometry (Malvern MasterSizer) and Scanning Electron Microscopy (SEM). Additionally, the mass fraction of free $\mathrm{Al}$ is measured using inductively coupled plasma optical emission spectrometry (ICP-OES). Note that the term "free Al" denotes the Al which can be further oxidized as opposed to $\mathrm{Al}$ contained in alumina. Therefore, this measurement provides the fraction of unburned $\mathrm{Al}$.

\subsection{Results}

All the results presented hereafter are obtained using the described QB at pressure $p=5 \mathrm{MPa}$ on a typical industrial $68 \%$ AP / $14 \%$ HTPB binder $/ 18 \% \mathrm{Al}$. The mean mass diameter of the $\mathrm{Al}$ powder used is $40 \mu \mathrm{m}$. Information about $\mathrm{Al}$ powder aggregation in cold conditions or about its dispersion in the propellant

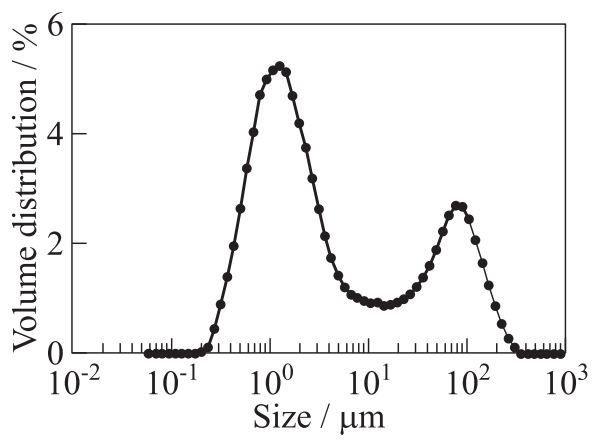

Figure 3 Size distribution of collected particles (standard $\mathrm{QB}, d_{\text {quench }}=40 \mathrm{~mm}$ ) matrix is not known. Figure 3 presents the measured size distribution with $d_{\text {quench }}=40 \mathrm{~mm}$. A classical bimodal distribution is obtained with two marked peaks. The first peak about $1 \mu \mathrm{m}$ is undoubtedly associated with alumina smoke. The second peak is about $90 \mu \mathrm{m}$ and might be at first glance attributed to final oxide residues since the quenching time is larger than the agglomerate burning time. However, the free $\mathrm{Al}$ mass fraction is measured to be $20.8 \% \pm 0.1 \%$, which surprisingly shows that there is still

a large amount of unburned Al. This casts a doubt upon this second peak which may not represent oxide residues as expected. Note that, although this work focuses on a single propellant, most propellants tested with this setup show a similar behavior, i. e., the presence of a marked second peak is concomitant with a large unburned $\mathrm{Al}$ fraction.

\subsection{Particle Sieving}

In order to understand the origin of the unburned $\mathrm{Al}$, the collected particles were screened into particles in different size ranges using sieves. Fourteen QB firings 


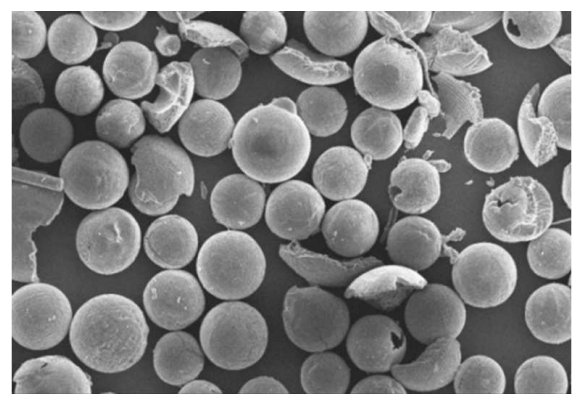

(a)

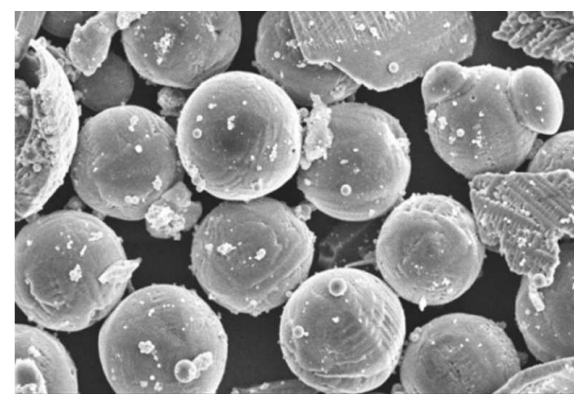

(b)

Figure 4 The SEM pictures of sieved particles: (a) 63-100 $\mu \mathrm{m}$; and (b) 28-36 $\mu \mathrm{m}$

were repeated in order to collect enough particles. The suspension was then sieved using 11 nylon sieves of different sizes, namely: 200, 125, 100, 80, 63, 50, $36,28,20,15$, and $5 \mu \mathrm{m}$. Particle total mass and free Al fraction were measured for each size range. SEM pictures were also taken as seen in Fig. 4. Spherical particles are mostly observed with some being broken. It is not known if broken particles are due to combustion (disruptive combustion), brutal quenching, or other reasons.

The mass collected for each size range is not presented here but is in agreement with what is expected from size granulometry (see Fig. 3). Of more interest is the free $\mathrm{Al}$ content as presented in Fig. 5. This graph represents the free $\mathrm{Al}$ mass fraction relative to the initial $\mathrm{Al}$ $Z_{\mathrm{Al}}$ with respect to the mean sieved particle size. The horizontal bar represents the size differ-

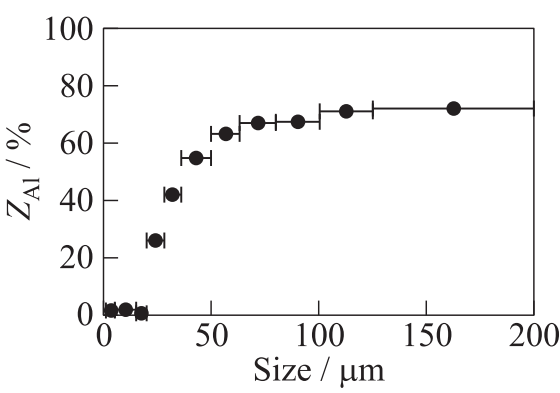

Figure 5 Free Al fraction relative to initial Al vs. particle size ence between two successive sieves. The first important result is that large particles have a high unburned $\mathrm{Al}$ fraction and, therefore, one may conclude that they are indeed the $\mathrm{Al}$ agglomerates. The $\mathrm{Al}$ content is relatively constant for the largest particles and then abruptly decreases for the particles between 20 and $80 \mu \mathrm{m}$. Below $20 \mu \mathrm{m}$, the particles are only composed of alumina $\mathrm{Al}_{2} \mathrm{O}_{3}$. This was also confirmed by energy dispersive X-ray spectrometry. The size of $20 \mu \mathrm{m}$ can be viewed as a limit between agglomerates and residues. Note that $Z_{\mathrm{Al}}$ seems to reach a plateau at roughly $70 \%$ which possibly means that even the largest agglomerates have undergone substantial combustion. 
As far as we know, only the work [1] reported Al content vs. particle size. They similarly found a one-to-one correspondence between size and free Al fraction. Their results show a fairly linear graph with an agglomerate/residue limit by $50 \mu \mathrm{m}$. However, it is anticipated that this law is not universal and may depend on agglomeration.

\subsection{Effect of Quenching Distance}

It can be postulated that the quenching distance is too small to allow particles to undergo a complete combustion. Therefore, a parametric study on the quenching distance is undertaken. This modification of the quenching distance can be obtained readily by increasing the distance $d_{\text {quench }}$ between propellant and quenching liquid but also by altering the sample orientation. Indeed, the strong recirculation induced by the rotation of the drum notably affects the streamlines as attested in Fig. 6 by numerical simulations (the description of which is deferred until next chapter). This figure shows a top view of the middle streamline from propellant surface for three different sample orientations: $\alpha=0^{\circ}, 45^{\circ}$, and $90^{\circ}$ (for $d_{\text {quench }}=40 \mathrm{~mm}$ ). The sample is represented by the square and the drum rotates from right to left. The case $\alpha=0^{\circ}$ (see Fig. $6 a$ ) corresponds to the baseline configuration where the sample faces the wall. As obvious from Fig. 6, the effective quenching distance $L$ is much larger than the "naive" value $d_{\text {quench }}$ because of the rotation of the streamlines. The computed effective quenching distances from the numerical simulations are $L=84,87$, and $97 \mathrm{~mm}$ for $\alpha=0^{\circ}$, $45^{\circ}$, and $90^{\circ}$, respectively, which is roughly twice larger than $d_{\text {quench }}$. Additionally, the present authors considered the case $d_{\text {quench }}=66 \mathrm{~mm}$ where the sample is located in the middle of the drum. In that case, the effective quenching distance is computed to be $L=103 \mathrm{~mm}$.

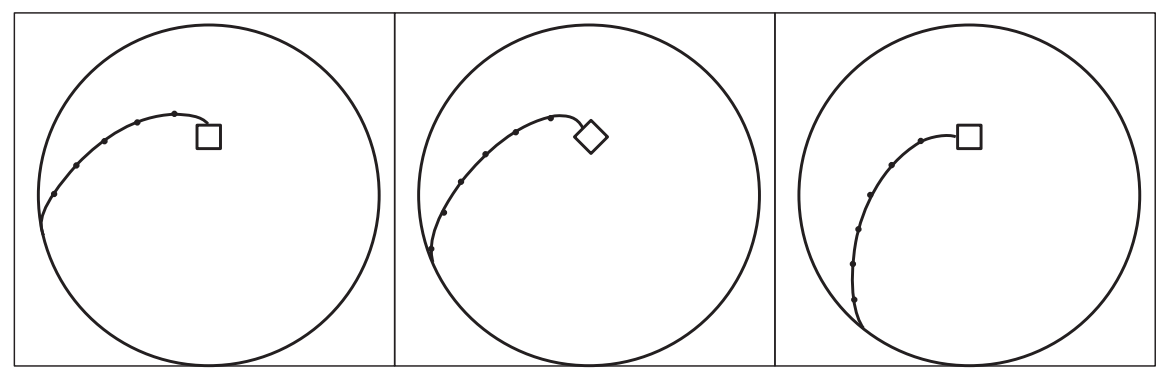

(a)

(b)

(c)

Figure 6 Streamlines for three different sample orientations obtained by numerical simulations $\left(d_{\text {quench }}=40 \mathrm{~mm}\right)$. The drum rotates from right to left: $(a) 0^{\circ}, L=84 \mathrm{~mm}$; (b) $45^{\circ}, L=87 \mathrm{~mm}$; and (c) $90^{\circ}, L=97 \mathrm{~mm}$ 
The four configurations were experimentally tested, i. e.:

(1) $d_{\text {quench }}=40 \mathrm{~mm}, \alpha=0^{\circ}$;

(2) $d_{\text {quench }}=40 \mathrm{~mm}, \alpha=45^{\circ}$;

(3) $d_{\text {quench }}=40 \mathrm{~mm}, \alpha=90^{\circ}$; and

(4) $d_{\text {quench }}=66 \mathrm{~mm}, \alpha=0^{\circ}$.

Although they have different effective quenching distances, there were no evident significant experimental effects on the size and Al fraction. Surprisingly, the results happen to be very similar to what is presented in Fig. 3. In addition, tests conducted on a configuration with $d_{\text {quench }}=20 \mathrm{~mm}$ showed again similar results. Therefore, it can be argued that the effective quenching distance has virtually no influence. This troublesome result may be explained by numerical simulations.

\section{NUMERICAL SIMULATIONS}

\subsection{Numerical Method}

The flow inside the QB can be addressed by two-phase numerical simulations. To this end, compressible Navier-Stokes equations are solved using the authors' in-house code CPS [16]. This code adopts a finite-volume technique on unstructured mesh. Conservative variables are calculated at the center of each computational cell whereas convective fluxes are computed at cell edges using an approximate Riemann solver (Roe scheme) for the gas phase and a donorcell type scheme for particle phase. Particle phase is treated in an Eulerian way using classical drag laws. The $\mathrm{Al}$ combustion model is the usual $D^{2}$ square model. Equations solved for the gas and particle phases can be found in [11]. An operator splitting is used for particle source terms (mass, momentum, and energy) when using explicit time-stepping: first, conservative variables $\mathbf{W}^{n}$ are updated without source terms to an intermediate state $\mathbf{W}^{*}$ for time step $\Delta t$. Then, the differential equation $d \mathbf{W} / d t=\mathbf{S}$ is solved from $\mathbf{W}^{*}$ to the final state $\mathbf{W}^{n+1}$. Presented computations are second-order accurate in space (Monotonic Upstream-Centered Scheme for Conservation Laws (MUSCL) approach) and second-order accurate in time using an explicit two-step Runge-Kutta algorithm. The time step is given by a Courant-Friedrichs-Lewy (CFL) criterion set to $\mathrm{CFL}=0.8$. In addition, turbulence effects are modeled through the Coakley's $k-\omega$ model.

The physical domain is here oversimplified and computations are performed in two dimensions. The domain meshed is the inside part of the drum as presented in Fig. 7. The sample holder is not discretized and only the propellant sample 


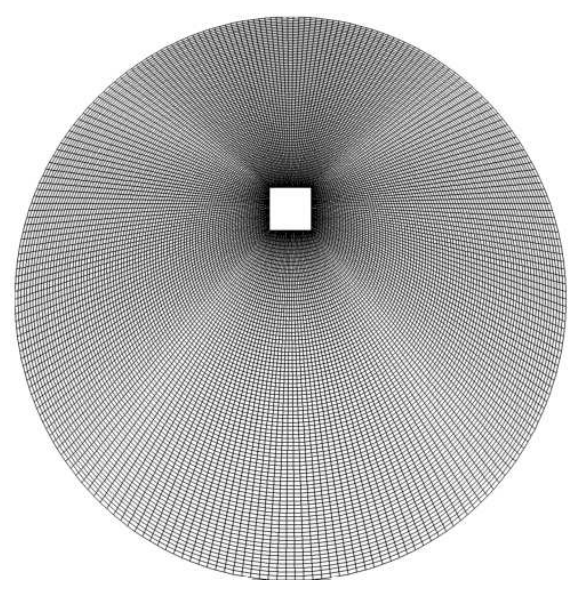

Figure 7 Mesh of the QB (22,000 quads)

appears as a 1-centimeter-size square. The mesh used here includes about 22,000 quads.

The boundary conditions on the QB walls are an imposed tangential velocity corresponding to a rotation rate of $3000 \mathrm{rpm}$. On a propellant surface, a constant gas mass rate $m$ $=12 \mathrm{~kg} / \mathrm{m}^{2} / \mathrm{s}$ and gas stagnation temperature $T=3400 \mathrm{~K}$ is prescribed. The particles are supposed to emerge from the propellant surface with gas velocity and at combustion temperature (assumed to be the $\mathrm{Al}$ saturation temperature $T_{\text {sat }}$ $\sim 2800 \mathrm{~K})$ and with mass fraction $f=6 \%$ (which means that $1 / 3$ of the total $18 \% \mathrm{Al}$ is likely to agglomerate). Particles are monodisperse with size $D_{\text {agg }}=100 \mu \mathrm{m}$. The propellant burnback is not accounted for and the geometry is, therefore, fixed. Let recall that the sample is inhibited everywhere except for the surface that faces the wall so that only the upper surface of the sample is burning. The initial conditions are given by $300 \mathrm{~K} \mathrm{~N}_{2}$ at $p=5 \mathrm{MPa}$.

\subsection{Simulation Results}

Figure 8 presents the simulation results for the case $d_{\text {quench }}=40 \mathrm{~mm}$ and $\alpha=0^{\circ}$ in terms of gas temperature and velocity vectors. As already highlighted, a strong recirculation flow is imposed by the rotation of the drum (see Fig. $8 b$ ). The velocity magnitude can reach up to $20 \mathrm{~m} / \mathrm{s}$ on the walls and remains rather high even in the vicinity of the propellant surface where it is typically 5 times larger than the injection velocity. If one assumes that gas temperature is a passive scalar (which is not exactly true close to the propellant surface due to $\mathrm{Al}$ combustion heat release), the temperature field is then similar to propellant gas mass fraction. From Fig. $8 a$, it can be concluded that propellant gases mix very rapidly with $\mathrm{N}_{2}$ due to the intense back flow. The propellant surface is, therefore, swept by "cold" (i.e., ambient temperature) pressurant which eventually leads to a quenching of $\mathrm{Al}$ droplets because of depletion in oxidizer. (Note that this quenching is not modeled in present computations and should be considered for further works.) The mixing thickness is about 3 $4 \mathrm{~mm}$ which is not enough to allow for complete particle combustion. Hence, the simulations explain that unburned agglomerates are experimentally found primarily because they are quenched early in their combustion stage. This is 


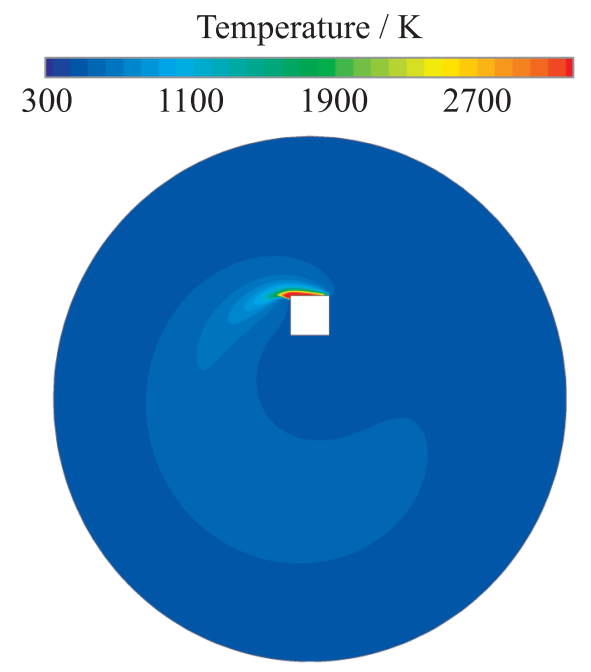

(a)

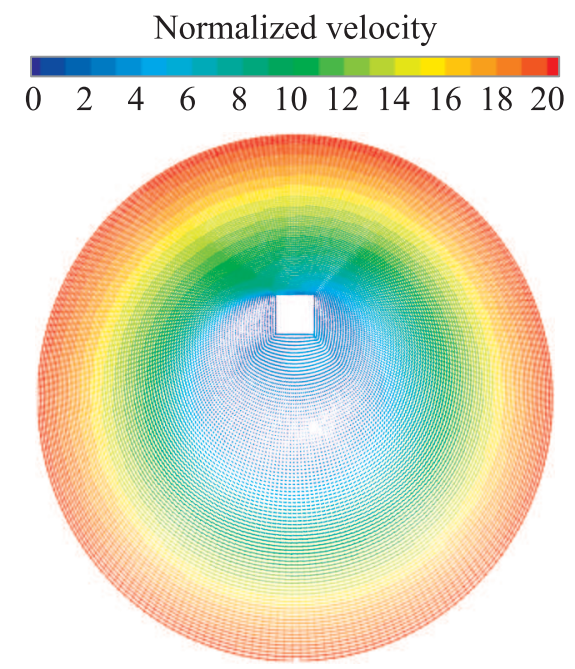

(b)

Figure 8 Simulation results for $\alpha=0^{\circ}$ : $(a)$ gas temperature; and $(b)$ gas velocity vectors (colored by velocity magnitude)

also coherent with the fact that combustion completion was rather insensitive to the apparent quenching distance since quenching occurs very early. Indeed, the computations were also performed for the other configurations (orientations and quenching distances) and showed a similar behavior. Eventually, present QB collects $\mathrm{Al}$ agglomerates rather than $\mathrm{Al}_{2} \mathrm{O}_{3}$ residues because of a rotation-induced $\mathrm{N}_{2}$ quenching.

\section{IMPROVED “2-IN-1" QUENCH BOMB}

As previously addressed, present QB is likely to collect particles that have been quenched by the cold $\mathrm{N}_{2}$ flow. Hence, in its standard configuration, it is not able to collect alumina residues (because the particles are quenched too early), nor $\mathrm{Al}$ agglomerates (because the particles may have presumably undergone partial combustion before quenching). In order to collect both agglomerates and oxide residues with the same setup, here, two simple modifications are proposed.

\subsection{Near-Surface Quenching (Al Agglomerate Collection)}

A near-propellant surface quenching is required to obtain the $\mathrm{Al}$ agglomerates produced at the propellant surface. It is indeed not known if particles quenched 


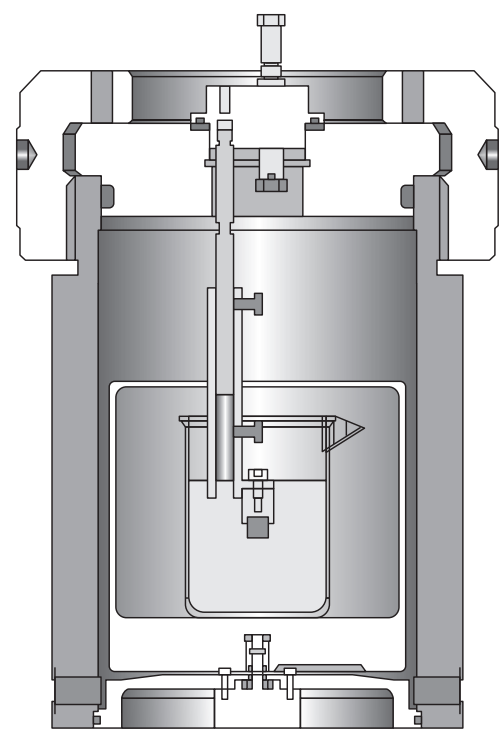

Figure 9 Sketch of the "dunked" QB

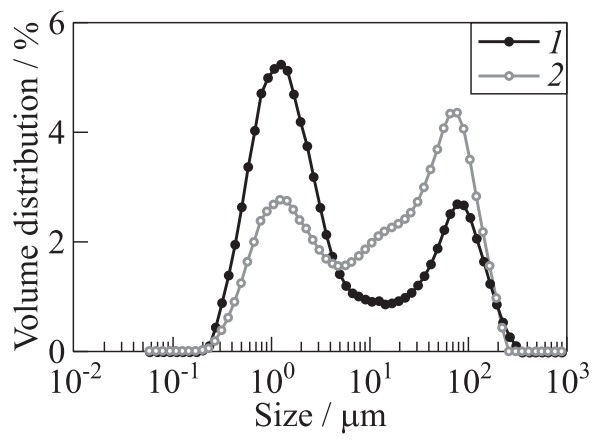

Figure 10 Size distributions in standard (1) and "dunked" QB (2) in the standard QB configuration are genuine nascent agglomerates since they might have undergone partial combustion. In order to quench burning droplets at the propellant surface, it is proposed to "dunk" the propellant directly into the quenching liquid as depicted in Fig. 9. The same bomb is used but the drum no longer rotates. A glass beaker filled with ethanol is placed in the bomb and the propellant is plunged inside and subsequently ignited. The setup is then operated as usual and the ethanol suspension is collected for further analysis.

The size distribution obtained in this configuration is presented in Fig. 10 together with the results obtained in the standard configuration (see Fig. 3). In this dunked version, the distribution is again globally bimodal although a weak third peak by $20-30 \mu \mathrm{m}$ seems to emerge and is visible as a "shoulder" of the second peak. The 1-micrometer smoke peak is still present although in lesser intensity since the particles were not allowed to reach complete combustion. (However, it is anticipated that the smallest Al particles can burn significantly before quenching which explains that smoke is still present.) An interesting result is that large agglomerates have a similar mode size, about $90 \mu \mathrm{m}$. This means that the standard QB quenches burning droplets in a very early stage of combustion since their size is similar to the size of agglomerates as quenched near propellant surface. This is coherent with what was inferred from simulations (see Fig. 8). Note that the near-surface quenching collects a larger amount of coarse particles, which obviously comes from an earlier halt of the combustion. The volume fraction of particle larger than $10 \mu \mathrm{m}$ is $32 \%$ in standard configuration and $55 \%$ in dunked version. The free metallic Al mass fraction was measured to be $25.5 \%( \pm 0.6 \%)$ which is higher than 
the $20.8 \% \pm 0.1 \%$ measured in the standard QB. Here again, this reflects a weaker combustion progress. The 20-30-micrometer "hidden" peak is possibly linked to virgin unagglomerated particles or even to small agglomerates that have experienced significant combustion.

The main result here is that the standard QB results are close to the nearsurface quenching results. This confirms again that the particles collected in the standard $\mathrm{QB}$ are mostly the $\mathrm{Al}$ agglomerates.

\subsection{Alumina Residues Collection}

As mentioned in introduction, collecting final oxide residues is not an easy task. Some techniques involve particle collection in plume exhausts but they are questionable because of possible breakup or coalescence in the nozzle. Other methods intend to sample particles inside a subscale motor which is also complex in order to keep an isokinetic sampling. Hence, the QB remains a simple and relevant setup.

It has been addressed that the standard QB cannot collect oxide residues since combustion is stopped prematurely by a rotation-induced gas quenching. A decrease in the spinning rate can be an alternative but numerical simulations conducted at $1000 \mathrm{rpm}$ also attested a significant gas mixing. Some studies (see, for example, [13]) proposed the use of an injection cane where the gas propellant flows through a cane before exiting in the vicinity of the drum wall. The idea is interesting; however, the published results were much scattered.

The simple idea chosen here is to replace the inert pressurant $\left(\mathrm{N}_{2}\right)$ by an oxidizing pressurant. In the present case, air and $\mathrm{CO}_{2}$ were both evaluated. The authors are aware that $\mathrm{CO}$ or $\mathrm{H}_{2} \mathrm{O}$ are the major oxidizing species found in solid propellant gases but they were not tested: $\mathrm{CO}$ is highly toxic and water vapor needs the setup to be preheated beforehand to avoid condensation which would result in significant modifications of the setup.

If an oxidizing ambiance is used, the ethanol must be replaced in order to avoid an exothermic reaction between oxidizing pressurant and flammable ethanol (actually, the present authors did the experiment, nevertheless). Ethanol was first replaced by water, which is unfortunately known to favor small alumina particles (smoke) flocculation [17]. This was indeed attested by zeta-potential measurements and later confirmed in the QB. The authors tried other (nonflammable) quenching liquids to limit this colloidal flocculation such as water with various surfactants or hydrofluoroethers but they all resulted in significant smoke aggregation. An illustration of this enhanced aggregation is shown in Fig. 11 which is a SEM picture of the collected particles in water for combustion in air (note that similar results stand for $\mathrm{CO}_{2}$ ). Large spherical particles are clearly visible but one may also notice a compact quasi-homogeneous medium actually composed of aggregated 1-micrometer alumina particles (smoke). 


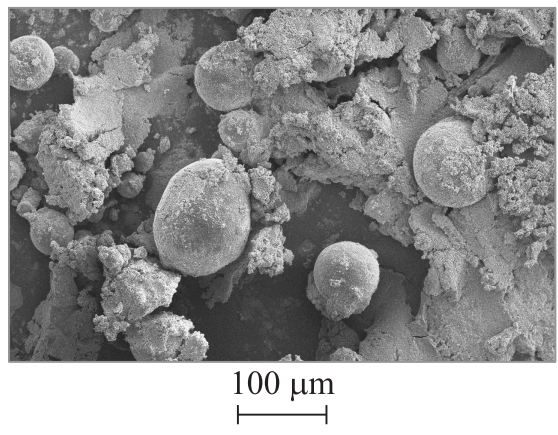

Figure 11 The SEM picture of particles collected in water, showing oxide residues as well as large aggregation of smoke

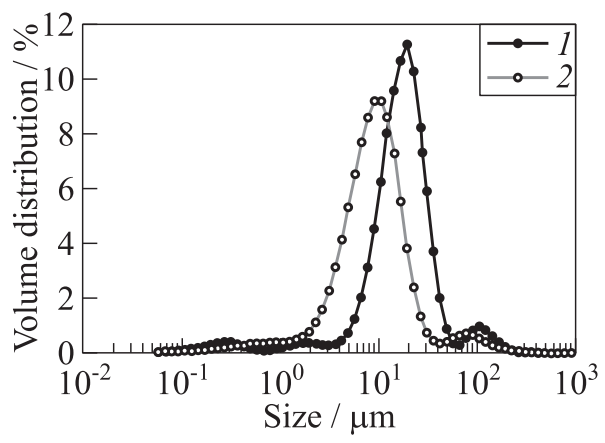

Figure 12 Size distributions for combustion in air (1) and $\mathrm{CO}_{2}(2)$
Size distributions obtained in air and $\mathrm{CO}_{2}$ ambiance are presented in Fig. 12. The first striking result is the absence of the large 1-micrometer smoke peak. Although the suspension was desagglomerated using ultrasonic device, it seems that smoke remains aggregated (as seen in Fig. 11) and sediments in the laser granulometry setup so that it cannot be seen in Fig. 12. Figure 12 shows a single major peak about $20 \mu \mathrm{m}$ for air and $10 \mu \mathrm{m}$ for $\mathrm{CO}_{2}$. It has been also confirmed those values by automatic processing of SEM pictures (such as in Fig. 11) and a single peak at the expected size was noticed. Free Al content was also measured and compiled in Table 1. There is virtually no Al left when the sample burns in an oxidizing atmosphere which means that collected particles are indeed the $\mathrm{Al}_{2} \mathrm{O}_{3}$ residues. The size of residues seems to depend slightly on the nature of the pressurant which is a new result and needs to be confirmed. Note, however, that the value of $20 \mu \mathrm{m}$ is reminiscent of the limit between agglomerates and residues in the standard QB (see Fig. 5).

As a partial conclusion, the presented "2-in-1" QB gives agglomerates of size $D_{\text {agg }} \sim 90 \mu \mathrm{m}$ and residues $D_{\text {res }} \sim 10-20 \mu \mathrm{m}$, the ratio of which $\beta$

Table 1 The QB results for three different pressurants (at $p=5 \mathrm{MPa})$

\begin{tabular}{ccc}
\hline Pressurant & Free Al content, $\%$ & Main size mode, $\mu \mathrm{m}$ \\
\hline $\mathrm{N}_{2}$ & 20.8 & 90 \\
$\mathrm{Air}$ & 0.5 & 20 \\
$\mathrm{CO}_{2}$ & 1.4 & 10 \\
\hline
\end{tabular}


$=D_{\text {res }} / D_{\text {agg }}$ is about $\sim 0.2$. This is a relatively low value compared with the scarce experimental data available. For instance, Glotov and Zhukov [18] found $\beta \sim 0.5$ whereas Zenin et al. [19] measured $\beta \sim 0.8$. Let remark that this value may also depend on pressure, oxidizing gases, or agglomerate size and is, therefore, not universal.

\subsection{Alumina Residues: Particle Analysis}

A closer look at the previous size distributions (see Fig. 12) reveals a puzzling result: despite the quasi-absence of $\mathrm{Al}$, there are still very large particles $(>100 \mu \mathrm{m})$.

In order to determine their nature, a particle sieving followed by a titration of the unoxidized $\mathrm{Al}$ was performed just as done in subsection 2.3. The results for the free $\mathrm{Al}$ fraction are the following: $1.5 \%$ for the 100-200-micrometer range and $1.8 \%$ for the $63-100$-micrometer range. Those very low values confirm that the largest particles are indeed oxide residues since they virtually contain no unburned $\mathrm{Al}$ left.

A detailed particle analysis was conducted on those large oxide residues. To this end, collected particles were embedded in Araldite and subsequently ion-polished with an argon plasma during $8 \mathrm{~h}$ (ion accelerating voltage $6 \mathrm{kV}$ ). Figure 13 presents macroscopic (Fig 13a) and SEM (Fig. 13b) pictures of the polished particle-containing araldite. In the SEM picture, the largest particles are clearly visible as white disks. Black holes correspond to air bubbles trapped during mixing between particles and araldite.

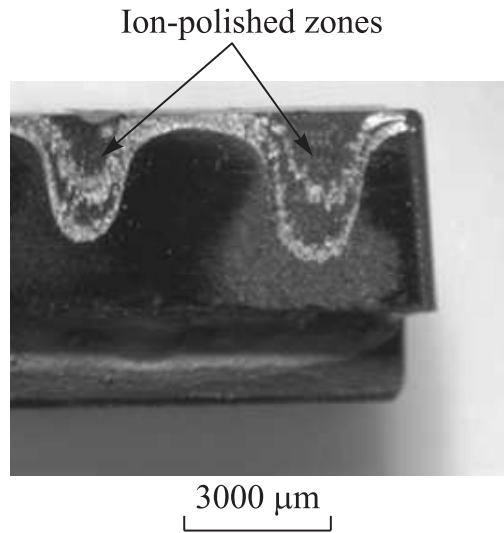

(a)

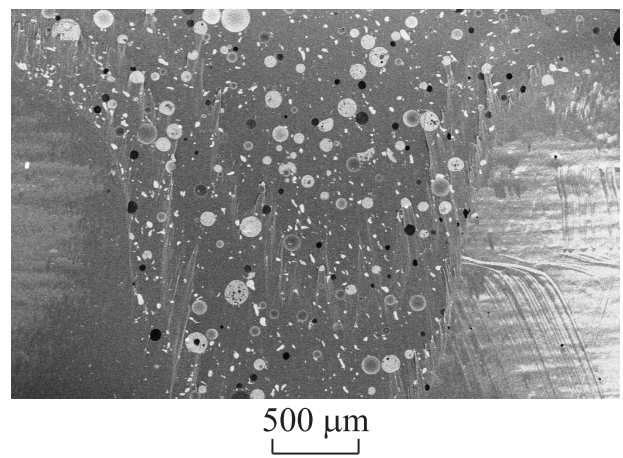

(b)

Figure 13 Marcoscopic $(a)$ and SEM (b) pictures of the polished particle-containing araldite 

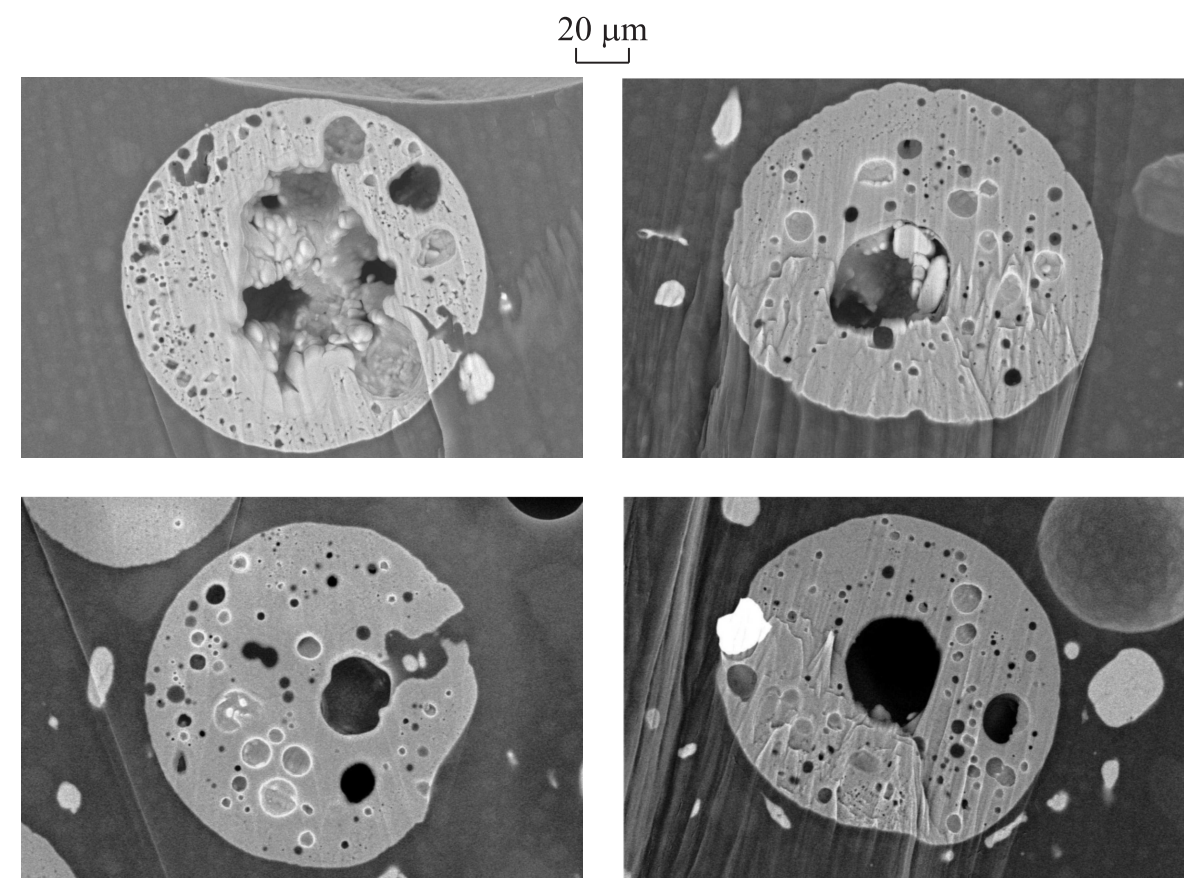

Figure 14 Selection of SEM pictures of large oxide residues

Figure 14 shows a selected compilation of SEM pictures of the largest oxide residues present. Their diameter is about $120-150 \mu \mathrm{m}$. Since they are polished, it is possible to observe the inner structure of the particles and, as clearly evidenced in Fig. 14, such particles are hollow. Many small pores are clearly visible with generally a large central cavity. Hollow residues were already reported, for instance, in [20]. Here, they are observed for both air and $\mathrm{CO}_{2}$ atmosphere although pictures presented in Fig. 14 were taken for a $\mathrm{CO}_{2}$ ambiance. The presence of those large hollow particles is generally neglected in simulations and their role is not well known so far.

\section{CONCLUDING REMARKS}

In this work, a standard QB is studied both experimentally and numerically. Experiments, conducted on a single propellant, show that the standard QB collects particles that still contain a significant amount of unburned Al. A sieving allows one to determine the free $\mathrm{Al}$ content vs. size: large particles are mainly $\mathrm{Al}$ whereas small particles are alumina; the boundary seems to stand by $20 \mu \mathrm{m}$. 
The quenching distance was increased to favor combustion completion but the results surprisingly do not depend on quenching distance. With the help of numerical simulations, the proposed scenario is that burning particles are swept by an intense back flow of inert pressurant $\left(\mathrm{N}_{2}\right)$ which eventually quenches particles at the propellant surface. This recirculating flow is induced by the rotation of the QB drum. The standard QB is modified into a "2-in-1" setup that allows for a measurement of both agglomerates and oxide residues. The agglomerates are quenched by directly plunging the propellant into the quenching liquid whereas oxide residues are obtained by replacing the inert pressurant by an oxidizing pressurant (air and $\mathrm{CO}_{2}$ ). Agglomerate and oxide residue sizes are found to be about 90 and $20 \mu \mathrm{m}$, respectively. Many large oxide residues are noted and found to be hollow.

\section{ACKNOWLEDGMENTS}

The authors would like to thank the French Space Agency CNES (Nathalie Cesco and Eric Robert) for funding and supporting this study.

\section{REFERENCES}

1. Sambamurthi, J., E. Price, and R. Sigman. 1984. Aluminum agglomeration in solidpropellant combustion. AIAA J. 22(8):1132-1138.

2. Duterque, J. 1996. Experimental studies of aluminum agglomeration in solid rocket motors. 4th Symposium (International) on Special Topics in Chemical Propulsion.

3. Price, E., and R. Sigman. 2000. Combustion of aluminized solid propellants. Solid propellant chemistry, combustion and motor interior ballistics. Eds. V. Yang, T. Brill, and W. Ren. Progress in astronautics and aeronautics ser. AIAA. 185:663688.

4. Babuk, V., V. Vassiliev, and V. Sviridov. 2000. Formation of condensed combustion products at the burning surface of solid rocket propellant. Solid propellant chemistry, combustion and motor interior ballistics. Eds. V. Yang, T. Brill, and W. Ren. Progress in astronautics and aeronautics ser. AIAA. 185:749-775.

5. Jackson, T.L., F. Najjar, and J. Buckmaster. 2005. New aluminum agglomeration models and their use in solid-propellant rocket simulations. J. Propul. Power 21(5):925-935.

6. Gallier, S. 2009. A stochastic pocket model for aluminum agglomeration in solid propellants. Propell. Explos. Pyrot. 34(2):97-105.

7. Beckstead, M. 2002. A summary of aluminum combustion. RTO/VKI special course on internal aerodynamics in solid rocket motors.

8. AGARD. 1986. Performance of rocket motors with metallized propellants. AGARD Advisory Report 230. North Atlantic Treaty Organization. 
9. Salita, M. 1995. Deficiencies and requirements in modeling of slag generation in solid rocket motors. J. Propul. Power 11(1):10-23.

10. Shimada, T., M. Sekiguchi, and N. Sekino. 2007. Flow inside a solid rocket motor with relation to nozzle inlet ablation. AIAA J. 45(6):1324-1332.

11. Gallier, S., and F. Godfroy. 2009. Aluminum combustion driven instabilities in solid rocket motors. J. Propul. Power 25(2):509-521.

12. Liu, T., and C. Hsieh. 1996. Analysis of agglomerate size from burning aluminized AP/RDX/HTPB propellants in quench bomb. J. Propul. Power 12(5):995-998.

13. Habu, H., T. Shimada, and H. Hasegawa. 2006. Study on $\mathrm{Al} / \mathrm{Al}_{2} \mathrm{O}_{3}$ agglomeration particle size distributions for solid propellants. AIAA Paper No. 2006-5249.

14. Jeenu, R., K. Pinumalla, and D. Deepak. 2010. Size distribution of particles in combustion products of aluminized composite propellant. J. Propul. Power 26(4):715723.

15. Hijlkema, J., P. Prévot, M. Prévost, and V. Mironov. 2011. Particle size distribution measurements in the Keldysh Research Centre experimental setup at ONERA. AIAA Paper No. 2011-5712.

16. Durand, P., B. Vieille, H. Lambare, P. Vuillermoz, G. Boure, P. Steinfeld, F. Godfroy, and J. Guery. 2000. CPS: A three-dimensional CFD code dedicated to space propulsive flows. AIAA Paper No. 2000-3864.

17. Atwood, A. 2008. Private communications.

18. Glotov, O., and V. Zhukov. 2008. The evolution of 100- $\mu \mathrm{m}$ aluminum agglomerates and initially continuous aluminum particles in the flame of a model solid propellant. II. Results. Combust. Explo. Shock Waves 44(6):671-680.

19. Zenin, A., G. Kusnezov, and V. Kolesnikov. 2000. Physics of aluminum particle combustion at convection. AIAA Paper No. 2000-0849.

20. Babuk, V., I. Dolotkazin, and V. Glebov. 2005. Burning mechanism of aluminized solid rocket propellants based on energetic binders. Propell. Explos. Pyrot. 30(4):281-290. 